\title{
Applicability of Framingham risk equations for studying a low-income Mexican population
}

Aida Jiménez-Corona, MD, MSc, PhD, (I) Ruy López-Ridaura, MD, MSc, PhD, (I) Ken Williams MS, (2) Ma Elena González-Villalpando, MD, (3) Jesús Simón, MD, ${ }^{(4)}$ Clicerio González-Villalpando, MD. ${ }^{(1,3)}$

\section{Jiménez-Corona A, López-Ridaura R, Williams K, González-Villalpando ME, Simón J, González-Villalpando C. Applicability of Framingham risk equations for studying a low-income Mexican population. Salud Publica Mex 2009;5 I:298-305.}

\begin{abstract}
Objective.To compare the predicted risk of coronary heart disease (CHD) and incident myocardial infarction (MI) using Framingham score equations with the observed rate of MI in Mexican subjects. Material and Methods. Longitudinal study that included I 667 men and women aged 35 to 64 years without $\mathrm{Ml}$ at baseline. Incident $\mathrm{MI}$ was defined by electrocardiogram or death certificate.The predicted risk of fatal $\mathrm{MI}$, non-fatal $\mathrm{MI}$, and both was calculated using Framingham score equations. Predicted to observed risk ratio of MI was estimated. Results. There were 34 incident $\mathrm{Ml}$ cases and 24 $\mathrm{MI}$ deaths (median follow-up 6.2 years). The score equations overestimated the prediction of incident $\mathrm{MI}$ and $\mathrm{CHD}$ death (ratio 2.27, 95\% Cl, I.19-3.34) and incident MI (ratio 2.36, $95 \% \mathrm{Cl}, 1.07-3.65)$ in men. Conclusions. The Framingham score overestimated incident $\mathrm{MI}$ and $\mathrm{CHD}$ death risk in men; however, other studies are needed to confirm our results for recalibrating the score for Mexican subjects.
\end{abstract}

Key words: myocardial infarction; mortality; prediction; Mexico
Jiménez-Corona A, López-Ridaura R, Williams K, González-Villalpando ME, Simón J, González-Villalpando C. Aplicabilidad del puntaje de Framingham en población mexicana de nivel socioeconómico bajo. Salud Publica Mex 2009;5 I:298-305.

\section{Resumen}

Objetivo. Comparar el riesgo predicho y observado de enfermedad coronaria (EC) e infarto al miocardio (IM) usando ecuaciones del puntaje de Framingham en individuos mexicanos. Material y métodos. Estudio longitudinal de I 667 hombres y mujeres de entre 35 a 64 años de edad y sin IM en la medición basal. IM se definió por electrocardiograma o certificado de defunción. Se estimó el riesgo predicho y la razón del riesgo predicho y observado de IM. Resultados. Durante el seguimiento (mediana de 6.2 años) hubo 34 casos y 24 defunciones por IM. El puntaje sobreestimó la predicción de IM y muerte por EC (razón 2.27, IC 95\% I.19-3.34) e IM incidente (razón 2.36, IC 95\% I.07-3.65) en hombres. Conclusiones. En este estudio, el puntaje de Framingham sobreestimó el riesgo de IM y muerte por IM en hombres; sin embargo, estos resultados necesitan ser confirmados por otros estudios, para la posterior recalibración del puntaje en población mexicana.

Palabras clave: infarto del miocardio; mortalidad; predicción; México

The Research Grant ROIHL 24799 of the National Heart Lung and Blood Institute, Bethesda, MD, USA, supported this work. Funding from the Consejo Nacional de Ciencia y Tecnologia CONACYT Grants 2092/M9303, F677-M9407, 3502-M9607 also helped in some parts of the study.

(I) Centro de Investigación en Salud Poblacional, Instituto Nacional de Salud Pública. Mexico.

(2) KenAnCo Biostats. San Antonio, Texas, USA.

(3) Centro de Estudios en Diabetes, AC. México.

(4) American British Cowdray Hospital. México.

Received on: January 22, 2009 • Accepted on: April 7, 2009

Address reprint requests to: Dra.Aida Jiménez-Corona.Av.Universidad 655, Col. Santa María Ahuacatitlán. 62508, Cuernavaca, Morelos, México E-mail: ajimenez@correo.insp.mx 
$\mathrm{I}_{(\mathrm{c}}^{\mathrm{n}}$ ncidence and prevalence of coronary heart disease (CHD), particularly myocardial infarction (MI), has increased in most regions of the world over the last decades. This trend is associated with a mounting prevalence of classic cardiovascular risk factors such as diabetes, dyslipidemia, hypertension, obesity, and smoking, among others. ${ }^{1-3}$ Worldwide, mortality from CHD has also risen, and available population-based studies confirm a high mortality rate in both sexes., ${ }^{4,5}$ In addition, some differences in morbidity and mortality from CHD have been documented by ethnicity and might be accounted for, in part, by different prevalences of the main cardiovascular risk factors. ${ }^{6-9}$

Currently, CHD prevention has focused on the identification of individuals at high risk by combining individual risk factors and reducing overall absolute cardiovascular risk. ${ }^{10-13}$ Several methods originated in specific populations combine the effect of some cardiovascular risk factors to calculate overall absolute risk. Specifically, the Framingham score equations estimate the risk of developing different cardiovascular outcomes (including fatal and non-fatal CHD) at 5 and 10 years of follow-up. ${ }^{14-16}$ The score usually includes age, blood pressure (BP), total cholesterol or LDL-cholesterol, HDL-cholesterol, and diabetes, and estimation is done separately by sex. Perhaps the equation most widely used is that which includes categorical variables to predict total $\mathrm{CHD},{ }^{15}$ since its application is easier in the clinical setting.

Previous reports have shown that the Framingham score overestimates cardiovascular risk in several populations, ${ }^{17-21}$ including Puerto Ricans ${ }^{16}$ and Spaniards. ${ }^{22}$ However, the accuracy of the Framingham score in other Hispanic populations such as Mexicans has been scarcely evaluated, in spite of being widely used to define timely therapeutic intervention, especially with cholesterol lowering drugs. In this study, we evaluated the accuracy of some of the Framingham risk equations ${ }^{14,15}$ to predict MI in a low-income Mexican populations, considering fatal and non-fatal MI both together and separately.

\section{Material and Methods}

\section{Study design}

The Mexico City Diabetes Study is a prospective, population-based cohort designed to describe the prevalence and incidence of diabetes and cardiovascular risk factors in low-income urban populations in Mexico City. The detailed methodology has been reported elsewhere. ${ }^{23}$ Briefly, a population-based sample of 2282 men and non-pregnant women aged 35 to 64 years from a low- income sector completed a baseline interview and physical examination in 1989-1990. Two follow-up visits were carried out in 1994-1996 $(n=1773)$ and in 1998-2000 $(n=$ 1764). A total of 1667 subjects were included in the present study, after exclusion of 86 subjects with previous MI corroborated by ECG, 492 without ECG at baseline, and 37 without Framingham score information. When comparing included and excluded subjects without MI at baseline, we found no differences with regard to sex, diabetes, serum cholesterol, and HDL-cholesterol; however, we observed significant differences in age (48.1 vs. 46.9 years old, respectively), hypertension (23.1 vs. 18.2\%, respectively), and current smoking (17.8 vs. $27.4 \%$, respectively).

\section{Risk factors assessment}

At baseline and follow up visits, participants completed risk factor questionnaires through a structured interview and a clinical examination including anthropometry, blood pressure (BP), and blood samples. Subjects were asked about their smoking habits. Systolic (SBP) and diastolic (DBP) blood pressures were measured three times (after resting for at least $5 \mathrm{~min}$ ) using a random zero sphygmomanometer (Hawksley, London). We used the average of the last two readings to classify BP levels. $\mathrm{BP}$ categories were defined according to the Fifth Joint National Committee on Hypertension definition (JNC $\mathrm{V})$ as follows: ${ }^{24}$ optimal BP (SBP $<120$ and DBP $<80$ $\mathrm{mmHg}$ ); normal BP (SBP 120-129 or DBP 80-84 mmHg); high normal BP (SBP 130-139 or DBP 85-89 mmHg); hypertension stage I (SBP 140-159 or DBP 90-99 mmHg), and hypertension stage II-IV (SBP $\geq 160$ or DBP $\geq 100$ $\mathrm{mmHg}$ ). Serum total cholesterol and HDL-cholesterol were determined by cholesterol-esterase and further classified into the following categories: $<200,200-239$, and $\geq 280 \mathrm{mg} / \mathrm{dL}$ for total cholesterol and $<35,35-44$, and $\geq 45 \mathrm{mg} / \mathrm{dL}$ for HDL-cholesterol. Blood pressure and cholesterol categorizations were made independently of the use of antihypertensive or lipid lowering drug treatment. Diabetes was diagnosed as fasting glucose $\geq 126$ $\mathrm{mg} / \mathrm{dl}$ (7.0 mmol/l), 2-hour glucose $\geq 200 \mathrm{mg} / \mathrm{dl}$ (11.1 $\mathrm{mmol} / \mathrm{l}$ ) or self-report and treatment with hypoglycemic medication. ${ }^{25}$ Left ventricular hypertrophy (LVH) was determined by resting standard ECG according to the Minnesota code criteria. ${ }^{26}$ In addition, metabolic syndrome (MS) was defined following the criteria of the National Cholesterol Education Program (NCEP) Adult Treatment Panel III (ATP III). ${ }^{27}$

Laboratory determinations were performed in the research laboratory of the Division of Clinical Epidemiology at the Medicine Department of the University of Texas Health Science Center at San Antonio, USA. The 
Institutional Review Boards of both The University of Texas Health Science Center and the Centro de Estudios en Diabetes approved the study protocol. Each participant gave informed consent.

\section{Ascertainment of incident and fatal myocardial infarction}

Incident MI comprised cases identified through followup visits by resting ECG or by death certificate. A resting standard 12-lead ECG was taken at each examination, with the subject in a supine position. A standard interpretation of ECGs at a reading center (Wake Forest University, EPICARE Center) was made using the Minnesota Code. We included all possible and probable MI based on the following codes: Q-QS pattern with 1.1-1.2.7, Q-QS and T wave pattern with 1.2.8-1.3, and T wave pattern with 5.1-5.3. ${ }^{26}$ To determine the vital status of the study population, a telephone interview was carried out for the whole sample and death certificates were obtained. Myocardial infarction was considered as cause of death when it was the underlying cause, and classified according to the International Classification of Diseases $10^{\text {th }}$ Rev. (ICD 10a, codes 410.0-410.9). ${ }^{28} \mathrm{Al}-$ though we had information about angina by using the Rose questionnaire, we did not include it as an outcome because of poor accuracy to differentiate angina in this population.

\section{Framingham score equations}

We used several specific equations to calculate the predicted probability of total CHD, incident MI, and $\mathrm{CHD}$ death. We first estimated the predicted risk of total CHD (including angina as possible outcome), applying the $\beta$-coefficients of Cox proportional hazards model obtained from the Framingham population by Wilson et al. ${ }^{15}$ that included age (predefined categories), current smoking, diabetes, blood pressure regardless of hypertensive treatment (predefined BP categories), serum cholesterol (predefined categories), and HDLcholesterol (predefined categories). In addition, we separately estimated the predicted probability of total CHD, incident MI (only hard outcomes), and CHD death applying the $\beta$-coefficients of non-proportional hazards Weibull accelerated failure time model obtained by Anderson et al. ${ }^{14}$ that included (in their continuous manner, when appropriate) age, sex, SBP or DBP, current smoking, HDL-C, diabetes, and ECG-LVH. For each participant, we obtained a 10-year predicted probability of CHD, incident MI, and CHD death with each of the equations described above. Assuming a constant rate, we estimated the predicted probability at a specific follow-up time using the equation $\mathrm{p}=1-\left[(1-\mathrm{r})^{\wedge}(1 / 10)\right]^{\wedge} \mathrm{t}$, where $r$ is the Framingham 10-year risk and $t$ is the specific follow-up for each subject.

\section{Data analysis}

The Framingham score variables were compared between men and women using mean, standard deviation (SD), median, percentiles, and proportions when appropriate. Observed incidence rates and their 95\% confidence interval $(95 \% \mathrm{CI})$ were calculated by the Kaplan-Meier method as the number of people who had fatal or non-fatal MI during follow-up, divided by person-years at risk per 1000 person-years. Age-adjusted incidence rates were estimated using the direct method taking the 2000 Mexican population as the standard population. On the basis of each of the Framingham score equations, we calculated the predicted number of cases (CHD, incident MI, and CHD death) as the sum of all individual predicted probabilities at specific follow-up time and calculated the predicted rate dividing the predicted number of cases by person-years at risk expressed as rates per 1000 person-years. We calculated the ratio of predicted rate over the observed rate from each equation for different outcomes (CHD, incident MI, and CHD death) and their 95\% CI by predefined age categories. The analyses were conducted using SAS 9.0 (SAS Institute Inc., Cary, NC) and Stata/ SE 9.0 (Stata Corporation, Texas).

\section{Results}

\section{Description of the study population}

Of 1667 subjects included in this study, 681 (40.9\%) were men and 986 (59.1\%) were women. Mean age was similar in both men and women. Prevalence of diabetes was $12.0 \%$ in men and $13.2 \%$ in women. Current smoking in men was more than twice the proportion in women. SBP and DBP were higher in men, while HDL-cholesterol and fasting glucose levels were higher in women (Table I).

During a median follow-up of 6.2 years (range 0.29.8 years), 58 subjects developed MI, 34 were detected by ECG (13 men and 21 women) and 24 by death certificate (14 men and 10 women). From cases diagnosed by ECG, 14 were classified as possible and 20 as probable MI. Age-specific incidence rate for MI increased in both sexes with age (Table II). Age-adjusted incidence rate was slightly higher, but not significant, in men (6.5 per 1000 person-years, 95\% CI 4.0-8.9) than in women (5.2 per 1000 person-years, 95\% CI 3.4-7.0), with a 1.3:1 men-to-women ratio. Age-adjusted incidence rates for 
Table I

BASELINE CARDIOVASCULAR RISK FACTORS in A LOW-INCOME MEXICAN POPULATION BY SEX.

The Mexico City Diabetes Study, February 1990-November 2000

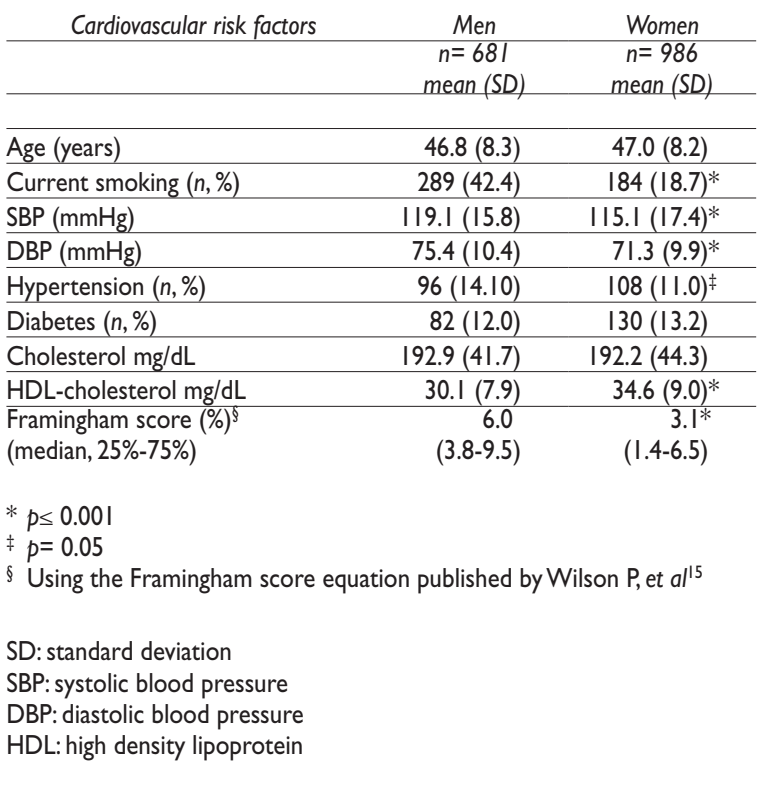

MI in subjects without and subjects with diabetes were 4.4 (95\% CI 3.0-5.8) and 10.1 (95\% CI 4.7-5.5) per 1000 person-years, respectively. As for fatal and non-fatal MI, age-adjusted incidence rate was higher in men than in women for the former (3.5 and 1.8 per 1000 personyears, respectively), and similar in both sexes for the latter (3.1 vs. 3.6 per 1000 person-years, for men and women, respectively).

\section{Observed and predicted myocardial infarction}

Table II shows a comparison between predicted and observed cases and rates of total CHD by age and sex, based on predefined categories of risk factors as suggested by Wilson et al. ${ }^{15}$ The Framingham score prediction overestimated the observed number of total CHD cases in both men (50 vs. 27 cases, respectively) and women (48 vs. 31 cases, respectively). Overall ratio of predicted / observed rate was $1.84(95 \% \mathrm{CI}, 1.15-2.53)$ for men and 1.55 (95\% CI, 1.01-2.08) for women. Both predicted and observed rates of CHD increased with age in men and in women; however, the overestimation tended to be smaller among older participants in both sexes. In addition, the ratio of predicted/observed rate

Table II

COMPARISON OF OBSERVED MYOCARDIAL INFARCTION AND PREDICTED ABSOLUTE CORONARY HEART DISEASE RISK BY SEX AND BY AGE CATEGORIES.

The Mexico City Diabetes Study, February I 990-November 2000

\begin{tabular}{|c|c|c|c|c|c|c|}
\hline Age (years) & Person-years at risk & $\begin{array}{l}\text { No. cases } \\
\text { observed }\end{array}$ & Predicted & $\begin{array}{c}\text { Rate* } \\
\text { observed } \\
(95 \% \text { Cl) }\end{array}$ & Predicted & $\begin{array}{c}\text { Ratio P/O } \ddagger \\
(95 \% \mathrm{Cl})\end{array}$ \\
\hline \multicolumn{7}{|l|}{ Men } \\
\hline $35-44$ & I 936.5 & 6 & 14 & $3.1(1.4-6.9)$ & 7.3 & $2.37(0.48-4.26)$ \\
\hline $45-54$ & I 473.4 & 8 & 19 & $5.4(2.7-10.9)$ & 12.7 & $2.34(0.70-3.97)$ \\
\hline $55-64$ & 888.1 & 13 & 17 & $14.6(8.5-25.2)$ & 19.0 & $1.29(0.61-1.98)$ \\
\hline Total & 4298.0 & 27 & 50 & $6.3(4.3-9.2)$ & 11.6 & $1.84(1.15-2.53)$ \\
\hline \multicolumn{7}{|l|}{ Women } \\
\hline $35-44$ & 2767.6 & 6 & 7 & $2.2(1.0-4.8)$ & 2.7 & $1.25(0.24-2.25)$ \\
\hline $45-54$ & 2180.7 & 7 & 20 & $3.2(1.5-6.7)$ & 9.0 & $2.79(0.72-4.86)$ \\
\hline $55-64$ & I 288.3 & 18 & 21 & $14.0(8.8-22.2)$ & 16.2 & $1.16(0.64-1.68)$ \\
\hline Total & 6236.6 & 31 & 48 & $5.0(3.5-7.1)$ & 7.7 & $1.55(1.01-2.08)$ \\
\hline \multicolumn{7}{|l|}{ Both } \\
\hline$\underline{35-44}$ & 4704.1 & 12 & 21 & $2.6(1.4-4.5)$ & 4.6 & I.8I (0.79-2.83) \\
\hline $45-54$ & 3654.1 & 15 & 39 & $4.1(2.5-6.8)$ & 10.5 & $2.55(1.26-3.84)$ \\
\hline $55-64$ & 2176.4 & 31 & 38 & $14.2(10.0-20.3)$ & 17.3 & $1.22(0.80-1.63)$ \\
\hline Total & 10534.6 & 58 & 98 & $5.5(4.3-7.1)$ & 9.3 & $\mathrm{I} .68(\mathrm{I} .26-2 . \mathrm{II})$ \\
\hline
\end{tabular}

* Per I 000 person-years

¥ Ratio of predicted to observed $(\mathrm{P} / \mathrm{O})$ absolute rates

Using the Framingham score equation published by Wilson $\mathrm{P}$, et al ${ }^{15}$ 
was 1.66 (95\% CI 1.13-2.20) for subjects with MS and 1.78 (95\% CI 1.02-2.53) for subjects without. When the ratio was estimated in subjects with $\geq 3$ risk factors of the Framingham score versus those with $<3$ risk factors, using the moderate risk level for each risk factor as cut point, we found that the overestimation was largely unchanged. Ratios were 1.81 (1.12-2.49) for subjects with $\geq 3$ risk factors and 1.59 (1.04-2.13) for those with $<3$. In both stratifications, the overestimation was smaller in older participants. (Data not shown.)

Table III presents a comparison between predicted and observed cases and rates of total CHD, incident MI, and CHD death by sex using scores for different equations. When the two equations for total CHD were used, the Framingham score overestimated the predicted number of CHD cases compared with the observed MI cases in both men (50 vs. 27 and 54 vs. 17 cases, respectively) and women (48vs. 31 and $40 v s .26$ cases, respectively). The ratio of predicted/observed rate using the first equation was 1.84 (95\% CI 1.15-2.53) in men and 1.55 (95\% CI 1.01-2.08) in women, whereas the ratio using the second equation was 3.17 (95\% CI
1.67-4.68) in men and 1.57 (95\% CI 1.67-2.17) in women. The main difference between the two equations is that the first includes most of the categorical variables, whereas the second includes continuous variables, as well as ECG-LHV. Since part of this overestimation can be explained by our not including angina as a potential outcome, we further explored more specific equations that used only "hard" outcomes: non-fatal MI, fatal CHD, or both. Using these equations, we still found overestimation in the whole population, but mainly in men, whereas in women predicted and observed rates were similar. The amount of overestimation was alike when the equations for incident MI and CHD death (ratio 2.27, 95\% CI, 1.19-3.34) and incident MI were used (ratio 2.36, 95\% CI, 1.07-3.65).

\section{Discussion}

Results from this study showed that the Framingham score equations for CHD systematically overestimated the predicted risk of MI (fatal and non-fatal) in a Mexican population. However, we found that the overestima-

Table III

COMPARISON OF OBSERVED FATAL AND NON-FATAL MYOCARDIAL INFARCTION AND PREDICTED ABSOLUTE RISK USING SEVERAL Framingham score equations.The Mexico City Diabetes Study, February I 990-November 2000

\begin{tabular}{|c|c|c|c|c|c|c|c|c|c|}
\hline & \multirow[t]{2}{*}{ Reference } & \multicolumn{2}{|r|}{ Outcome } & \multirow[b]{2}{*}{$\begin{array}{l}\text { Person-years } \\
\text { at risk }\end{array}$} & \multicolumn{2}{|c|}{ No. cases } & \multirow{2}{*}{$\begin{array}{c}\text { Rate* } \\
\text { Observed } \\
(95 \% \mathrm{Cl})\end{array}$} & \multirow[b]{2}{*}{ Predicted } & \multirow[b]{2}{*}{$\begin{array}{l}\text { Ratio P/O cases } \\
(95 \% \mathrm{Cl})\end{array}$} \\
\hline & & Predicted & Observed & & 0 & $P$ & & & \\
\hline $\operatorname{Men}(n=68 \mathrm{I})$ & \multirow{3}{*}{ Wilson $\mathrm{P}^{15}$} & \multirow{3}{*}{ CHD } & \multirow{3}{*}{ Fatal and non-fatal MI } & 4298.0 & 27 & 50 & $6.3(4.3-9.2)$ & 11.6 & I.84 (I.15-2.53) \\
\hline Women $(n=986)$ & & & & 6236.6 & 31 & 48 & $5.0(3.5-7.1)$ & 7.7 & $1.55(\mathrm{I} .0 \mathrm{I}-2.08)$ \\
\hline Both $(n=1667)$ & & & & 10534.6 & 58 & 98 & $5.5(4.3-7.1)$ & 9.3 & $1.68(1.26-2.1 \mathrm{I})$ \\
\hline Men $(n=670)$ & \multirow{3}{*}{-Anderson $\mathrm{HM}^{14}$} & \multirow{3}{*}{$\mathrm{CHD}$} & \multirow{3}{*}{ Fatal and non-fatal MI } & 4265.9 & 17 & 54 & $4.0(2.5-6.4)$ & 12.7 & $3.17(1.67-4.68)$ \\
\hline Women $(n=979)$ & & & & 6202.1 & 26 & 40 & $4.2(2.9-6.2)$ & 6.4 & $1.57(1.67-2.17)$ \\
\hline Both $(n=1649)$ & & & & 10468.0 & 43 & 95 & $5.5(4.3-7.1)$ & 9.1 & $2.20(1.55-2.86)$ \\
\hline Men $(n=670)$ & \multirow{3}{*}{ Anderson $\mathrm{HM}^{14}$} & \multirow{3}{*}{$\begin{array}{l}\text { Incident MI } \\
\text { and CHD death }\end{array}$} & \multirow{3}{*}{ Fatal and non-fatal MI } & 4265.9 & 17 & 38 & $4.0(2.5-6.4)$ & 8.9 & $2.27(1.19-3.34)$ \\
\hline Women $(n=979)$ & & & & 6202.1 & 26 & 20 & $4.2(2.9-6.2)$ & 3.2 & $0.76(0.46-1.05)$ \\
\hline Both $(n=1649)$ & & & & 10468.0 & 43 & 58 & $5.5(4.3-7.1)$ & 5.5 & $1.35(0.95-1.76)$ \\
\hline Men $(n=666)$ & \multirow{3}{*}{ Anderson $\mathrm{HM}^{14}$} & \multirow{3}{*}{ Incident MI } & \multirow{3}{*}{ Non-fatal MI } & 4265.9 & 13 & 30 & $3.1(1.8-5.3)$ & 7.1 & $2.36(1.07-3.65)$ \\
\hline Women $(n=974)$ & & & & 6202.1 & 21 & 16 & $3.4(2.2-5.2)$ & 2.6 & $0.74(0.42-1.07)$ \\
\hline Both $(n=1640)$ & & & & 10468.0 & 34 & 46 & $3.3(2.3-4.6)$ & 4.4 & $1.36(0.90-1.83)$ \\
\hline $\operatorname{Men}(n=657)$ & \multirow{3}{*}{ Anderson $\mathrm{HM}^{14}$} & \multirow{3}{*}{ CHD death } & \multirow{3}{*}{ Fatal MI } & 4216.0 & 4 & 7 & $0.9(0.3-2.5)$ & 1.7 & $1.85(0.03-3.67)$ \\
\hline Women $(n=958)$ & & & & 6115.8 & 5 & 4 & $0.8(0.3-2.0)$ & 0.7 & $0.70(0.10-1.31)$ \\
\hline Both $(n=1615)$ & & & & 10331.8 & 9 & II & $0.9(0.5-1.7)$ & 1.1 & $1.21(0.43-2.00)$ \\
\hline $\begin{array}{l}\text { * Per I } 000 \text { perso } \\
\text { ₹ Ratio of predict }\end{array}$ & served (P/ & & & & & & & & \\
\hline
\end{tabular}


tion was consistent only in men after using equations for specific outcomes such as incident MI and CHD death. Hence, we assumed that most CHD events in this population might be due to MI, at least in men, so overestimation in this group appears to be true.

The Framingham score equations for CHD risk assessment were developed in a predominantly middle-class non-Hispanic white population ${ }^{14,15}$ and have not been extensively validated for other ethnic groups. These score equations have been widely reported to overestimate the risk of predicted CHD in European, ${ }^{17-19,21}$ Japanese, ${ }^{29}$ Chinese, ${ }^{20}$ and Native American populations, ${ }^{16}$ but there is less information about Hispanic populations. ${ }^{16}$ An evaluation of the Framingham equations in Puerto Rican ${ }^{16}$ and Spaniard ${ }^{22}$ populations found that they significantly overestimated the risk of $\mathrm{CHD}$, although these results are not necessarily applicable to other Hispanic groups. Clearly, CHD risk overestimation depends on the study population and ranges from $20 \%$ to $50 \% \cdot{ }^{17-21,30}$ As in our analysis, in many others the overestimation effect has been more remarkable in men than in women, ${ }^{20,21}$ partly because of the unfavorable baseline cardiovascular risk profile in the former. Among explanations for overestimation of $\mathrm{CHD}$ predicted risk are the differences in the prevalence of the score variables, the possible differential interaction between variables or with unmeasured covariates, and the low incidence of CHD morbidity and mortality among these target populations compared with the Framingham population..$^{22,30}$

A few studies have reported an underestimation of CHD using the Framingham score, including one on an aboriginal population from Australia, ${ }^{31}$ and some others from a number of minority population groups from Europe as well as from Asia and Africa. ${ }^{32}$ Furthermore, there is evidence of an important underestimation in populations with high levels of socioeconomic deprivation and high mortality rates for cardiovascular diseases. ${ }^{33}$ Particularly, these populations have reported low mortality from $\mathrm{CHD}$, which is also related to other cardiovascular risk factors not included in the score. In addition, there is evidence that the Framingham score underestimated the CHD risk in subjects with diabetes, ${ }^{34,35}$ which may be related to the absence of glycemic control and diabetes duration among the score variables.

Risk calculators have been generated from the Framingham Heart Study to predict CVD risk in asymptomatic patients, but the accuracy of these risk predictors is somewhat limited in applicability among certain populations, and some well-known risk factors are not incorporated..$^{36}$ These are known limitations of the Framingham risk score, although the Framingham
Heart Study is an ongoing project and forthcoming risk prediction models will incorporate additional risk factors.

In order to evaluate selection bias due to exclusion criteria, we compared included versus excluded subjects and we observed that the former were older, had a higher percentage of hypertension, and smoked less than the latter. As two of the three characteristics were worse in the included subjects, we assumed that if a selection bias were present, it could contribute slightly to overestimation of the MI prediction. Because of the similar response rate during follow-up examinations, lost to follow-up related to the lack of information on MI (incidence or mortality) ascertainment was null.

A limitation to our study is our not including angina as an outcome. Rose questionnaire does not differentiate adequately the diagnosis in this population or in other non-Caucasian populations, ${ }^{37}$ and its inclusion would have led to a misclassification of the main outcome of our analysis. It could be argued that the exclusion of angina as an outcome might explain at least part of the overestimation using the general equation. However, the use of ECG to identify incident MI even in the absence of any symptom, rather than using strict clinical and enzymatic criteria, as does the original Framingham study to establish the predictive equation, increases our number of observed outcomes and probably helps identify some of the angina cases.

Another limitation to our study was the small number of observed cases, which did not let us make a strong conclusion about the amount of overestimation of the risk for the score variables. In addition, we were unable to generate a specific equation for the study population; moreover, we need evidence from larger studies to assess the recalibration procedure of the Framingham score in the Mexican population. Although the Framingham score equations have been shown to accurately predict CHD with the use of a recalibration, ${ }^{16,29,30}$ it would be useful to have risk profiles specifically developed for the Mexican population.

Several guidelines ${ }^{10-13}$ that have been employed to identify populations at high-risk of developing CHD and of dying are consequently based on scores such as those of the Framingham study. The final aim of all these instruments is to establish preventive measures that accord with the risk level of the subjects, including initiation of antihypertensive or antihyperlipidemic medication. The clinical implications of these decisions depend on the sensitivity and specificity of the scores in specific groups, so we should use appropriate guidelines in each case to avoid errors in risk estimation.

In conclusion, regardless of the Framingham score equation used, the prediction of CHD and MI (fatal 
and non-fatal) in this population appears to be overestimated, particularly in men; we therefore need more information to support this evidence and to generate a specific equation aimed at the Mexican population.

\section{Acknowledgements}

The authors would like to thank the residents of the neighborhoods who participated in the study. Authors express their acknowledgement to the Fundación Mexicana para la Salud, Mexico City, Mexico, for providing administrative support.

\section{References}

I. Kirchhoff M, Davidsen M, Bronnum-Hansen H, Hansen B, Schnack $\mathrm{H}$, Eriksen LS, et al. Incidence of myocardial infarction in the Danish MONICA population 1982-1991. Int J Epidemiol 1999;28(2):2 I I-218. 2. Jones DW, Chambless LE, Folsom AR, Heiss G, Hutchinson RG, Sharrett $A R$, et al. Risk factors for coronary heart disease in African-Americans: The Atherosclerosis Risk in Communities Study 1987-1997. Arch Intern Med 2002; 162(22):2565-257I.

3.Velazquez-Monroy O, Rosas-Peralta M, Lara-Esqueda A, Pastelin HG, Grupo ENSA 2000, Sánchez-Castillo C, et al. Prevalence and interrelations of non-communicable chronic diseases and cardiovascular risk factors in Mexico. Final outcomes from the National Health Survey 2000. Arch Cardiol Mex 2003;73:62-77.

4. Perez G, Pena A, Sala J, Roset P, Masia R, Marrugat J.Acute myocardial infarction case fatality, incidence and mortality rates in a population registry in Gerona, Spain, 1990-1992. REGICOR Investigators. Int J Epidemiol 1998;27:599-604.

5. Rosamond WD, Chambless LE, Folsom AR, Cooper LS, Conwill DE, Clegg $\mathrm{L}$, et al. Trends in the incidence of myocardial infarction and in mortality due to coronary heart disease, 1987 to 1994. N Engl J Med 1998;24(I3):86I-867.

6. Mitchell BD, Stern MP, Haffner SM, Hazuda HP, Patterson JK. Risk factors for cardiovascular mortality in Mexican-Americans and non-Hispanic whites:The San Antonio Heart Study. Am J Epidemiol 1990;131:423-433. 7. Greenlee RT, Naleway AL,Vidaillet $H$. Incidence of myocardial infarction in a general population:The Marshfield Epidemiologic Study Area.WMJ 2002;101:46-52.

8. Lowe LP, Greenland P, Ruth KJ, Dyer AR, Stamler R, Stamler J. Impact of major cardiovascular disease risk factors, particularly in combination, on 22year mortality in women and men. Arch Intern Med 1998;|58:2007-20I4. 9. Bobak M, Hense HW, Kark J, Kuch B,Vojtisek P, Sinnreich R, et al. An ecological study of determinants of coronary heart disease rates: A comparison of Czech, Bavarian and Israeli men. Int J Epidemiol 1999;28:437-444

10. National Institutes of Health. Third Report of the National Cholesterol Education Program Expert Panel on Detection, Evaluation, and Treatment of High Blood Cholesterol in Adults (Adult Treatment). Bethesda (MD): National Institutes of Health, 2002.

II. Recommendations of the Second Joint Task Force of the European and other Societies on Coronary Prevention. Prevention of coronary heart disease in clinical practice. Eur Heart J 1998; 19:1434-1503.

12. British Cardiac Society, British Hyperlipidemia Society, British Hypertension Society, British Diabetic Association. Joint British recommendations prevention of coronary heart disease in clinical practice. Heart 1998;80(Suppl 2):SI-S29.

13. Jackson R. Guidelines on preventing cardiovascular disease in clinical practice. BMJ 2000;320:659-660.

14. Anderson HM,Wilson PWF, Odell PM, Kannel WB. An updated coronary risk profile. A statement for health professionals. Circulation 1991;83:356-362.

I5.Wilson PWF, D'Agostino RB, Levy D, Belanger AM, Silbershatz H, Kannel WB. Prediction of coronary heart disease using risk factors categories. Circulation 1998;97:1837-1847.

16. D'Agostino RB, Grundy S, Sullivan L,Wilson PWF.Validation of the Framingham coronary heart disease prediction scores: Results of a multiple ethnic groups investigation. JAMA 2001;286:180-187.

17. Empana JP, Ducimetière P,Arvelier D, Ferrières J, Evans A, Ruidavets JB, et al. Are the Framingham and PROCAM coronary heart functions applicable to different European populations? Eur Heart J 2003;24(2I):|903-19|1.

18. Thomsen TF, McGee D, Davidsen M, Jorgensen. A cross-validation of risk-scores for coronary heart disease mortality based on data from the Glostrup Population Studies and Framingham Heart Study. Int J Epidemiol 2002;31:817-822.

19. Brindle P, Emberson J, Lampe F,Walker M, Whincup P, Fahey T, et al. Predictive accuracy of the Framingham coronary risk score in British men: prospective cohort study. BMJ 2003;327:1267-I272.

20. Liu J, Hong Y, D'Agostino RB, Wu Z, Wang W, Sun J, et al. Predictive value for the Chinese population of the Framingham CHD risk assessment tool compared with the Chinese multi-provincial cohort study. JAMA 2004:291(21):2591-2599.

21. Hense HW, Schulte H, Löwel H, Assmann G, Keil U. Framingham risk function overestimates risk of coronary heart disease in men and women from Germany —results from the MONICA Augsburg and PROCAM cohorts. Eur Heart J 2003;24:937-945.

22. Alvarez-Cosmea A, Diaz-Gonzalez L, Lopez-Fernandez V, Prieto-Diaz A, Suarez-Garcia S. Comparison of the SCORE and Framingham models in calculating high cardiovascular risk for a sample of males within the 45-65 age range in Asturias, Spain. Rev Esp Salud Publica 2005;79: 465-473.

23. Stern MP, Gonzalez C, Mitchell BD, Villalpando E, Haffner SM, Hazuda HP. Genetic and environmental determinants of type II diabetes in Mexico City and San Antonio. Diabetes 1992;41:484-492.

24. Joint National Committee on Detection, Evaluation, and Treatment of High Blood Pressure: the fifth report of the Joint National Committee on Detection, Evaluation, and Treatment of High Blood Pressure (JNCV). Arch Intern Med 1993;153:154-183.

25.World Health Organization. Definition, diagnosis and classification of diabetes Mellitus and its complications: Report of a WHO consultation. Part I: Diagnosis and classification of Diabetes Mellitus. Geneva:WHO, 1999.

26. Prineas R, Crow R, Blackburn H.The Minnesota Code Manual of Electrocardiographic Findings. Littleton (MA): John Wrigth-PSG, 1982. 27. Grundy SM, Cleeman JI, Daniels SR, Donato KA, Eckel RH, Franklin BA, et al. Diagnosis and management of the Metabolic Syndrome:An American Heart Association/National Heart, Lung, and Blood Institute Scientific Statement. Circulation 2005; I 12:2735-2752.

28. Pan American Health Organization. Clasificación Estadística Internacional de Enfermedades y Problemas Relacionados con la Salud (CIE-I0). Washington, DC: PAHO, 1995.

29. Suka M, Sugimori H,Yoshida K. Application of the updated Framingham risk score to Japanese men. Hypertens Res 200I;24:685-689.

30. Marrugat J, D'Agostino R, Sullivan L, Elosua R, Wilson P, Ordovas J, et al. An adaptation of the Framingham coronary heart disease risk function to European Mediterranean areas.J Epidemiol Community Health 2003;57:634-638. 
3I.Wang Z, Hoy WE. Is the Framingham coronary heart disease absolute risk function applicable to aboriginal people? MJA 2005; 182:66-69. 32. Cappuccio FP, Oakeshott P, Strazzullo P, Kerry SM. Application of Framingham risk estimates to ethnic minorities in United Kingdom and implications for primary prevention of heart disease in general practice: cross sectional population based study. BMJ 2002;325: I 27I-I275.

33. Brindle PM, McConnachie A, Upton MN, Hart CL, Smith GD,Watt GCM. The accuracy of the Framingham risk-score in different socioeconomic groups: a prospective study. Br J Gen Pract 2005;55:838-845.

34. Folsom AR, Chambless LE, Duncan BB, Gilbert AC, Pankow JS.

Prediction of coronary heart disease in middle-aged adults with diabetes.

Diabetes Care 2003;26:2777-2784.
35. Coleman RL, Stevens RJ, Retnakaran R, Holman RR. Framingham, SCORE and DECODE risk equations do not provide reliable cardiovascular risk estimated in type 2 diabetes. Diabetes Care 2007;30:1292-1294.

36. Pocock SJ, McCormackV, Gueyffier F, Boutitie F, Fagard RH, Boissel JP.A score for predicting risk of death from cardiovascular disease in adults with raised blood pressure, based on individual patient data from randomized controlled trials. BMJ 200I;323:75-8I.

37. Fischbacher CM, Bhopal R, Unwin N,White M,Alberti KGMM. The performance of the Rose questionnaire in South Asian and European origin populations: a comparative study in Newcastle, UK. Int J Epidemiol 200I;30:1009-1016. 